AC 2008-1979: WHEN CIVIL ENGINEERING TECHNOLOGY IS ELEVATED TO CIVIL ENGINEERING, WHAT CAN FILL THE TECHNOLOGY VOID

James Lambrechts, Wentworth Institute of Technology 


\title{
When Civil Engineering Technology is Elevated to Civil Engineering, What Can Fill the Technology Void?
}

\begin{abstract}
Currently, graduates with civil engineering technology degrees from 4-year institutions can eventually become registered professional civil engineers in 39 states. Many students choose the technology path in higher education because the instruction they receive is viewed as more practical and 'hands-on'. The CET program at Wentworth is thriving, and has gained considerable recognition over the past decade, with employers of our graduates saying that their new employees are indeed well prepared technically for the civil engineering tasks. However, with its recent action to adopt the ASCE Policy Statement 465, the National Council of Examiners of Engineers and Surveyors (NCEES) is essentially saying that technology programs will no longer qualify graduates for licensure. Without the possibility of professional registration, many parents will no longer allow their child to even consider going to an institution for four years of training. In light of expected plummeting enrollments, we are beginning the process to remold our CET program to be full civil engineering, and this may well be an arduous journey, because we want to retain our roots in 'hands-on' education while satisfying the requirements for full engineering instruction. However, this departure from civil engineering technology would leave a void in the preparation of civil engineering 'technologists' both for site engineering and the traditional "number-cruncher" in the office. It would appear that there will be an increasing demand for technologists for both field and office engineering, but career path potential has not yet been established in education and industry. The technologist will be in ever greater demand as the educational background and expectations of graduating civil engineers who directly pursue their Master's degree grow. This paper presents our deliberations on both; how to elevate the C.E.technology to full engineering while retaining the 'hands-on' heritage, and thoughts on the future need for the 'new' technology that will be needed to keep the U.S. civil engineering profession a globally competitive workforce.
\end{abstract}

\section{Introduction}

The civil engineering profession is about to experience what appears to be a major "sea-change" in the background preparation of under-graduates in ABET accredited colleges and universities. The American Society of Civil Engineers has for a number of years had a goal to "raise the bar" as to the qualifications for achieving professional licensure as civil engineers (and related specialty branches available in some states). Not only will post-graduate education be necessary (either a Master's degree or 30 credits of approved study), but the new ABET criteria appears likely to require major changes in the form and content of under-graduate education for civil engineering. What will be the impacts of these changes for Civil Engineering Technology education? As it has been known in recent years, CET in about 25 four-year institutions has provided a sound educational background to begin training for the practice of civil engineering. A CET graduate from many 4-year schools can calculate rebar sizing, runoff quantity, pavement thickness, BOD and COD treatment requirements, perhaps as well as a graduate from a civil engineering school. Granted, the educational basis in CET is somewhat less theoretical than a student would receive in a full civil engineering curriculum. However, the CET graduate can 
perform the work tasks needed in the design and construction industry, and has to this point in time been able to eventually become a registered professional civil engineer.

But there are many indications that in the near future, the only candidates who will qualify to take the PE exam for professional civil engineering licensure will be those who have achieved a bachelors degree from a full civil engineering school. This does not bode well for otherwise successful and thriving CET programs.

This paper uses our Civil Engineering Technology bachelor's degree program at Wentworth Institute of Technology to exemplify the deliberations that will be going on in approximately 25 colleges and universities that have four-year CET programs. The context of discussion for this paper can be framed by first asking a series of questions: 1. What will the future civil engineering bachelor's degree recipient be ready to do when first entering the work place?; 2 . Is there not going to be a strong need for civil engineering technologists in the future practice of civil engineering?; 3. Does the C.E. Technologist position not deserve recognition with some form of professional certification or licensure?; and 4. How could such a civil engineering technologist gain admission to the PE exam, without having to go back and earn a full $\mathrm{CE}$ bachelors degree and the added 30 post-graduate credits?

\section{What is Civil Engineering Technology?}

Over the past 15 to 20 years, Civil Engineering Technology at our school has been a healthy educational program. In the last 6 years, our graduating class has increased from 27 to 46 , and that growth appears to be continuing with 75 students in the current sophomore class. All of our graduates obtain positions in the design or construction business, and more than half are employed on the day they graduate. Although most of our graduates obtain civil engineering positions in the New England region, a growing number venture to distant areas across the U.S. Employers who have just recently hired a civil engineering technology graduate often note pleasant surprise that their new employees are indeed well prepared technically to undertake a diverse spectrum of civil engineering tasks and challenges presented to them. We hear comments that in the practice of engineering design, our C.E.Technology students are more focused on problem solving than graduates from Full Civil Engineering programs, who are sometimes noted by employers as being more interested in analyzing problems than in reaching design conclusions. Although data are incomplete, we 'hear' that quite a few of our graduates eventually obtain registration as Professional Engineers (which is often a requirement for career advancement at many civil engineering design firms).

The Civil Engineering Technology program at Wentworth Institute of Technology is summarized in Table 1. Much of the content is driven by the requirements of ABET-TAC ${ }^{1}$, because a school must have an accredited program to be competitive in attracting high school students. The four-year program at Wentworth is therefore quite similar to other 4-year C.E.Technology programs at various schools in the U.S. There are variations on the base program, with some schools including one or more courses on estimating, scheduling, or other aspects related to construction management. In some regards, our four year program is not too different from the current offerings in a number of full civil engineering programs. 
The ABET curriculum requirements for C.E.Technology and Civil Engineering had been somewhat parallel until a few years ago. Both criteria were established largely on input to ABET from the American Society of Civil Engineers. The Engineering curriculum required higher level of mathematics focus, and calculus-based instruction in physics and throughout the courses of the curriculum. Civil Engineering programs also provide detailed instruction in four design disciplines, as opposed to the three required for C.E.Technology. So the Technology degree is a somewhat less theory-based course of study in civil engineering, however, the analytical content of numerous courses is just as prevalent.

\begin{tabular}{|l|l|}
\hline Freshman Year - Fall Semester & Junior Year - Fall Semester \\
\hline Intro. to Design and Construction Profession & Structural Analysis I \\
\hline Chemistry I & Dynamics \\
\hline English I & Applied Fluid Mechanics \\
\hline College Mathematics I & Humanities or Social Science Elective \\
\hline & Applied Calculus and Differential Equations \\
\hline Freshman Year - Spring Semester & Junior Year - Spring Semester \\
\hline Construction Graphics & Mandatory Co-op Work Experience \\
\hline Fundamentals of Construction & Junior Year - Summer Semester \\
\hline English II & Structural Analysis II \\
\hline College Mathematics II & Hydraulic Design \\
\hline College Physics I & Soil Mechanics \\
\hline Sophomore Year-Fall Semester & Structural Steel Design \\
\hline Surveying I & Senior Year - Fall Semester \\
\hline Structural Mechanics I & \multicolumn{1}{|c|}{ Mandatory Co-op Work Experience } \\
\hline Social Science Elective & Senior Year - Spring Semester \\
\hline Social Science Elective & Highway and Pavement Design \\
\hline Calculus I & Reinforced Concrete Design \\
\hline Sophomore Year - Spring Semester & C.E. Technical Elective \\
\hline Surveying II & Humanities or Social Science Elective \\
\hline Structural Mechanics II & Water and Wastewater Treatment \\
\hline Materials, Testing and Quality Control & Senior Year - Summer Semester \\
\hline Technical Communications & Professional Practice \\
\hline Calculus II & Senior Design in Civil Engr. Technology \\
\hline Sophomore Year - Summer Semester & C.E. Technical Elective \\
\hline \multicolumn{1}{|c|}{ Recommended Co-op Work Experience } & Humanities or Social Science Elective \\
\hline
\end{tabular}

Table 1. Summary of the Civil Engineering Technology program at Wentworth

It is significant that the course of study at Wentworth provides detailed introductory instruction in five design disciplines, and we also require our students to complete two mandatory semesters of co-op employment, as listed in Table 1. These two 4-month work experiences provide most students a clear focus on their future, and the faculty notice real changes in student attitudes after each co-op period. Thus, after four years of study, we provide our students the tools and 
experience needed to function as well-trained entry level civil engineers or civil engineering technologists, who can perform design tasks and monitor and coordinate construction.

\section{Why Must C.E. Technology Education Change?}

A significant shadow is now being cast upon our currently successful C.E. Technology program by the recent actions of the National Council of Examiners of Engineers and Surveyors (NCEES). In their September 2006 national convention, the NCEES adopted Policy Statement 465 of the American Society of Civil Engineers (ASCE) as the key element of their future model law for registration of civil engineers ${ }^{2,3}$. The recommendation from NCEES to each state Board of Professional Registration is to require that all candidates for professional license as civil engineer both possess a Bachelor of Science in Civil Engineering and have obtained 30 credits of additional post-graduate education. When the NCEES recommendation is adopted in Massachusetts, it appears that graduates with Civil Engineering Technology degrees will no longer qualify as prospective candidates for professional registration. NCEES is recommending that the model law be adopted for implementation in 2015, but the exact timing of such adoption is solely up to each state's licensing board.

The issue of professional licensure is huge, because the lack of possible registration will surely be the death-knell of our civil engineering technology program. Parents of high school students are savvy to professional registration. The question of future professional licensure is often raised by high school students and their parents when visiting the WIT campus or in phone inquires. Currently, this is not a major issue, as many states permit CET graduates to become registered civil engineers (38 with CET degrees, and 3 others with MSCE after CET). However, in most of these states, the CET graduate must acquire an extra 2 to 4 years of civil engineering practice before being permitted to take the Professional Engineer's examination. The licensing board in each state sets the criteria for licensure in civil engineering, and there are substantial variations between states. Some may continue to accept CET graduates for C.E. licensure while others may adopt the ASCE recommendations that the BS degree be in civil engineering.

In Massachusetts, a graduate from the Wentworth CET program must practice civil engineering for 8 years before being permitted to take the P.E. exam, while a bachelor's graduate from one of the state's several university civil engineering programs is permitted to take the P.E. exam after just four years of civil engineering work experience. However, several other states require just 6 or 5 years of engineering practice before CET graduates are allowed to take the P.E. exam. But this begs a question of whether the average civil engineering student with a bachelor's degree is really ready to stamp design drawings after just four years of work experience? And it takes only three years of experience if that student were to have first acquired a Master's degree in civil engineering.

These current conditions cause some prospective students to not enter Wentworth, as both the prospective students and/or their parents are quite well informed on the issues of professional licensure. Furthermore, the mobility of a WIT graduate with a Massachusetts P.E. registration is somewhat limited because a few states currently do not permit comity of professional 
registration for CET graduates. This latter fact alone has in recent years caused a few students to leave our school after two years of successful study when they realize the potential future impact of the restricted license comity, particularly in Florida.

So it is becoming increasingly and painfully apparent that our successful C.E.Technology program at Wentworth will have to be elevated to the full civil engineering level of academic intensity. This means our program will need to provide: greater level of mathematics achievement (all students taking Calculus III and Differential Equations as separate courses); calculus-based physics instruction; and greater emphasis on calculus and theory-based derivations throughout the basic mechanics courses and in civil engineering design courses. This can be accomplished, but what will we have to abandon to make room for the elevated instruction? And how will it be possible to retain our 'moniker' for being 'hands-on' in our educational model? And what about the students who struggle with upper-level calculus? But who make excellent civil engineering technologists? This question causes me to wonder when in the last four decades did I last need to use an eigenvalue, or did I worry about the direction of an eigenvector? Our deliberations on the "hands-on" is discussed a bit later, but the first discussion is over what is to be included in the bar raising?

\section{"Raising the Bar" for Civil Engineering}

The stated objective of ASCE is to "raise the bar" for entry into the profession of civil engineering; the concern being that the BSCE degree awarded today does not prepare the graduate to the level of education that was provided 55 or 40 years ago 4 . Many of us 'oldtimers' agree that our under-graduate education of the 1960's and early 1970's was more intense and technically demanding than currently required. In her recent book, Galloway compares the higher level education needed in 1900 and in 2000 between civil engineering and medicine, and notes that it still only takes four years of academic study to become a P.E. in civil engineering, whereas it now takes a minimum of 8 years of study to qualify to become an M.D. And the number of credit hours to achieve the bachelor's degree in civil engineering has been reduced in the past 30 to 40 years. But ASCE is trying to do more than simply "put the bar back where it was" a half century ago. There will also be a different "form of jump" required of the undergraduate civil engineering student, in getting to the bachelors degree level, and a second educational jump required to attain professional licensure.

In 2004, ASCE published "Body of Knowledge for the $21^{\text {st }}$ Century: Preparing the Civil Engineer for the Future"3. There were 15 outcomes set forth by ASCE as technical and professional practice capabilities being needed for entry into the professional practice of civil engineering. ABET has adopted most of these outcomes for its 2008-2009 criteria for acceptance of under-graduate civil engineering programs, which is listed in Table 2.

However, ASCE has updated and expanded the Body of Knowledge (BOK) in a second edition ${ }^{5}$. The full report that was just released by ASCE in February 2008. There are now 28 outcomes, which in some regards are further divisioning of the initial 15. ASCE is now recommending that candidates for professional licensure should in the future achieve all 28 outcomes as prerequisite for entry into "Practice of Civil Engineering at the Professional Level". ASCE will soon be 
providing further guidance as to which must be gained during undergraduate education, which would be gained in the post-graduate study, and which would be gained as Engineer-in-Training.

The program must demonstrate that graduates can:

1. Apply knowledge of mathematics through differential equations, calculus-based physics, chemistry, and at least one additional area of science, consistent with the program educational objectives..

2. Apply knowledge of four technical areas appropriate to civil engineering.

3. Design a system, component, or process in more than one civil engineering context.

4. Explain basic concepts in management, business, public policy, and leadership.

5. Explain the importance of professional licensure.

Table 2 -ABET-EAC 2008-9 Curriculum Requirements for Accreditation of Civil Engineering Programs ${ }^{6}$

\section{What will Undergraduate Civil Engineering Education be in the Future?}

So the requirements set forth by ABET-EAC for 2008-9 will likely remain for a number of years. These do represent a substantial shift from previous requirements. ASCE is indicating that substantial changes may be needed in curricula for under-graduate education of civil engineers ${ }^{5}$. The vision expressed by ASCE is that the under-graduate degree in civil engineering may well in the future just serve as a "pre-engineering" degree, much like "pre-med" or "pre-law" programs of today. The inclusion of additional, non-technical outcomes in the BOK may further lessen the technical capabilities of new bachelor degree civil engineering graduates. Obviously, we must wait to see how ASCE will address the 28 outcomes in view of under-graduate education achievement. But it appears clear that the civil engineering bachelor's degree graduate will not have a level of technical skills that we 'old-timers' did. There will be more of the 'soft- subjects' covered in under-graduate education. This is not to say that a Professional Engineer should not have an appreciation and understanding for the numerous 'professional practice' topics, in fact they should. But why not gain this knowledge in post-under-graduate study? The simple explanation could well be that ASCE only has direct influence over the curriculum taught at the under-graduate level.

While this and the coming requirement to also achieve the +30 credits of post-graduate study as prerequisite for being considered for professional licensure will eventually improve the profession of civil engineering in the U.S., there will be period of adjustment in the entry-level workplace. This point is further addressed in a later section. 


\section{Is It Possible to Change to Full Civil Engineering, but Retain Hands-On Approach?}

As we at Wentworth begin pondering the development of a full Civil Engineering program, we quickly reach a quandary. First, just what sort of a program are we supposed to have? Second, and most importantly for our reputation, how can we retain our school's 'hands-on' approach to education, while fulfilling higher curricular standards required by ABET in the upcoming 2008-9 requirements. Fortunately, our initial efforts at developing a full civil engineering curriculum will also be following the requirements of ASCE BOK-2 ${ }^{\text {nd }}$ edition. Our substantial task is to meet the ABET-EAC requirements within the context of our 'hands-on' educational model. A significant shift will occur with the incorporating of a calculus-basis into physics and into the fundamental engineering mechanics courses. There will need to be a greater theoretical basis for developmental technical courses. These changes will have to occur within the 15 week semesters, so some aspects of our current courses will have to be replaced.

At Wentworth, the 'hands-on' aspect of education has several meanings, including; demonstrative laboratory exercises in the engineering mechanics, hydraulics, materials and soil mechanics classes, problem-solving laboratory exercise in structural analysis and structural design, software application exercises in highway design, and design experiences in municipal planning, foundations, earthwork, water and wastewater treatment subjects. Surveying, which is obviously hands-on, is also part of our present curriculum. What of these elements can we retain, or do we need to retain?

We must be cognizant of the 'hands-on' elements that enhance student learning, and this assessment is best made internally. Comment is sought from students and graduates as to the more valuable elements of the educational experience in each course. We also actively seek input from employers of our co-op students and graduates, regarding the types of technology they need to see available in new-hires, and what are the upcoming technologies. While it is definitely not our goal to simply produce CAD operators who know how to run some of the design software, the civil engineering industry is lagging in its application of computer and CAD-based technology ${ }^{7}$. So the better versed a graduate is in currently prevalent design technologies, which must include knowing how to QC the results, the more immediately valuable that new employee will be to the civil engineering firm. There will be no easy solution to our quest to retain 'hands-on' in the new civil engineering curriculum. In fact, that melding of theory and 'hands-on' may well be our toughest task.

\section{What Will the Entry-Level Civil Engineer of the Future be Able to Do?}

Civil engineering firms have complained for many years that new graduates should be better prepared to enter the work place. How will this be improved when the BOK-2 ${ }^{\text {nd }}$ edition requirements are eventually adopted by ABET? That answer depends on the direction that civil engineering programs at colleges and universities take in meeting the new requirements of the BOK- $2^{\text {nd }}$ edition 28 outcomes have to be included in future under-graduate education. Indications are that substantial curriculum changes will be required. ASCE has stated that the student who achieves a bachelor degree in civil engineering will essentially only be acquiring a 'pre-engineering' level of knowledge. There will be greater emphasis on history, global awareness, business and economics, environment and ethics. It just may be that the BS in civil 
engineering will not suffice for an entry-level position in civil design or construction firms, and that the new-normal for entry to civil engineering practice will be the Masters Degree. How will this new-normal level affect the civil engineering industry in the U.S.?

As civil engineering education is broadened to be more of a pre-engineering course of study, then for a while (maybe a decade) employers of new bachelor degree graduates will have to adjust to the fact that the technical capability they expect will not yet have been bestowed on the 'new hire'. While 'industry' realizes that new graduates will need training on particular firm specific processes by the firm and work-place practices, 'industry' will not want to have to educate new civil engineers on technical matters that they 'should have learned in college'. But this is the situation that the $\mathrm{BS}+30$ requirement and the $\mathrm{BOK}$ second edition are forming for the civil engineering industry which is used to hiring primarily bachelor degree graduates. Are the civil engineering graduate school programs ready to quickly step up and provide the technical education that will be otherwise lacking?

The ultimate goal of ASCE is to have a society of civil engineers who are not just numbercrunching analysts, but who instead will be globally aware leaders and influential citizens of the U.S. and world society of tomorrow. It is obvious that most politicians today do care about infra-structure, to the point that the mention of infra-structure helps get them elected. However, maintaining infra-structure is costly, and runs contrary to the politicians' mantra of cutting taxes. ASCE's report card on the state of U.S. infra-structure shows continuing poor grades, year after year. International business relations in future years will demand greater breadth of view and background. As such, ASCE's expansion of the BOK to include 10 specific professional educational outcomes to increase background on ethics, business, global awareness, history and politics is laudable. But, just where does that leave the civil engineering industry in its need for those number-crunching analysts? The medical profession does not need everyone in medical schools to become an M.D., and in fact the number of entrants to medical school is controlled to limit the number of doctors produced. This limitation in effect creates a need for lesser educated positions in medicine. If the goal of ASCE is to model civil engineering education along the lines of medical and legal professions, then it is suggested that a fuller parallel needs to be established at the outset of the 'bar-raising'.

\section{There Is Going to be a Large Future Need for Civil Engineering Technologists}

It would appear that civil engineering technology may be poised for a reincarnation of a sorts. There is a need today for civil engineering technologists in both the design office and in field and site engineering positions. A number of schools provide Construction Engineering education, which can provide the background needed for many field and construction engineering positions. But is there enough of the civil engineering content in construction engineering curricula to satisfy the needs of the future site civil engineer who will be paired with the project construction manager and owner's project manager?

A second, future demand for civil engineering technologists appears likely to develop from the U.S. civil engineering design industry as it undergoes the metamorphosis that will be driven by the ASCE BOK-2 $2^{\text {nd }}$ ed. curricular requirements. Employers will quickly realize that entry-level bachelor degree civil engineers are not as capable of performing design work as their 
predecessors a decade previous were. The new BSCE graduates will have had substantially less technical training in undergraduate school. Furthermore, the new Master's degree recipient may be more well versed in research/analysis topics than in practical design because many graduate school professors are heavily research oriented by the requirements of their institutions, and many have little or no 'real world' design experience.

Civil engineering technology education as it currently exists could well fill the gap, and perhaps would lead to a 'sea-change' in the manner of employment throughout the civil engineering design industry. What design firms will really need in the future will be a large number of highly skilled civil engineering technologists, and a lesser number of project design managers to coordinate and review the design work. These project design managers will have to be highly educated in the many facets of the $\mathrm{BOK}-2^{\text {nd }}$ ed., but those engineering technologist doing the CAD-designs and analyses would not all have to have the full BOK-2 ${ }^{\text {nd }}$ ed. educational basis. Of course, some or many civil engineering bachelor degree graduates will go on to Master's degree work straight out of under graduate school, and they then too will be in the pool of entry-level civil designers. By their fuller educational attainment, these more thoroughly educated civil engineers would be expected to rise fast through the ranks of design responsibility. The technologists, on the other hand, would rise more slowly, or perhaps move laterally within a design firm. A really good civil engineering designer can be as great a value as a project design manager. The design office of the future will likely be quite a different operation from that of the recent past as computer applications using 3-D and 4-D modeling linked with GPS become widely accepted and more the norm.

Civil engineering is not a one size fits all industry! The goal of the ASCE BOK will fulfill one present and future deficiency, but it leaves much yet to be filled in. A much broader view is needed to complete an educational landscape that will satisfy the broad horizon of the civil engineering profession. The civil engineering technologist should be the first addition to professional levels. There is already an under-graduate program of study in ABET-TAC. The missing link is to provide the CET graduate with a level of distinct and recognizable professional standing, and a career path to attaining full Professional Engineer licensure that does not entail "going back to GO", i.e. doing the under-graduate training all over again.

So if there is to be greater need for civil engineering technologists, both with field/site aspirations or more of the design inclination, how will these experts be recognized by the profession? The civil engineering and construction industry should now start to look forward to differentiate the civil engineering and site engineering technologists from the civil engineer in responsible charge. The single title of registered Professional Engineer that has historically been applied will no longer be sufficient. Both levels of the civil engineering industry deserve future professional recognition. With this evolution we will have even greater need for the civil engineering technology education than has existed in the past. But the path to this position must be recognized and pursued by ASCE, because it is ASCE that is leading the charge to the BS+30 and the $\mathrm{BOK}-2^{\text {nd }}$ edition. It would appear that the civil engineering profession is going to evolve to be similar to the medical and legal professions wherein there are doctors and nurse practitioners, and lawyers and para-legals. 


\section{Summary}

There are not yet definitive answers to the two questions posed in this paper. The evolution of our 4-year Civil Engineering Technology program to full engineering will to the extent possible retain elements of Wentworth's current 'hands-on' approach. Our new program will have to satisfy the 2008-9 ABET-EAC requirements, and we will probably struggle to retain our historic experiential educational model. This is certainly a work in progress.

The second question of "What Can Fill the Technology Void?" seems to be just an opening to what will likely be a long and involved discussion throughout the civil engineering industry. It would appear inevitable that to retain a healthy and competitive civil engineering design and construction industry, the U.S. will need to quickly develop a cadre of civil engineering technologists who will need to both be educated in the civil engineering fundamentals and be trained in the effective and efficient use of a variety of the upcoming design tools. The U.S. civil engineering industry must be able to compete on a cost effective basis with firms around the world. The answer to this question can in part be provided by ASCE if and when a broader context is developed that more fully encompasses the future C.E. work place where both the professional engineers and the other allied-professional are accepted in an integrated approach that can synergistically power the engine of the business of U.S. civil engineering.

\section{Bibliographic Information}

(1) ABET-TAC, Criteria for Accrediting Engineering Technology Programs, ABET, Inc., Baltimore, MD, 2005.

(2) NCEES,"Council votes for more education," Licensure Exchange, Volume 10, Issue 5, 2006, p.3.

(3) ASCE, "Policy Statement 465", adopted by Board of Direction, 19 Oct. 2004. $\{\underline{\text { http://www.asce.org/pressroom/news/policy details.cfm?hdlid=15 }}$ \}

(4) Galloway, P., “The $21^{\text {st }}$ Century Engineer: A Proposal for Engineering Education Reform," Civil Engineering, November 2007, ASCE, pp. 46-57 and 98-104.

(5) ASCE, "Preparing the Civil Engineer of Tomorrow by 'Raising the Bar'," Civil Engineering, September 2007 , pp. 64-71.

(6) ABET-EAC, Criteria for Accrediting Engineering Programs, ABET, Inc., Baltimore, MD, 2007.

(7) CE News, "Civil Engineering Technology, The State of Practice," November 2007, ZweigWhite Information Services, Chicago, IL, 8 pages. 